УДК 581.192+547.914

\title{
ИЗВЛЕЧЕНИЕ ЭКСТРАКТИВНЫХ ВЕЩЕСТВ И БЕТУЛИНА ИЗ БЕРЕСТЫ ПРИ ВОЗДЕЙСТВИИ СВЧ-ПОЛЯ
}

\author{
() Е.Н. Коптелова", Н.А. Кутакова, С.И. Третьяков
}

\author{
Северный (Арктический) фредеральный университет им. М.В. Ломоносова, \\ Набережная Северной Двины, 17, Архангельск, 163002 (Россия), \\ e-mail:elen-koptelova@yandex.ru
}

Исследован процесс извлечения экстрактивных веществ и бетулина из бересты при воздействии СВЧ-поля. Показано, что при использовании микроволновой обработки в СВЧ-поле продолжительность процесса экстракции сокращается в 10-15 раз по сравнению с экстракцией методом настаивания. Изучено влияние основных параметров на процесс СВЧ-экстрагирования экстрактивных веществ из бересты.

Методом ВЭЖХ количественно установлено содержание бетулина в составе экстрактов бересты.

Ключевые слова: береста, СВЧ-экстракция, экстрактивные вещества, бетулин.

\section{Введение}

Бетулин относится к тритерпеноидам ряда лупана, является основным компонентом экстрактивных веществ (ЭВ) коры березы. Состав ЭВ в промышленной бересте (в процентах по массе) по литературным данным [1] следующий: бетулин $(78,1)$; лупеол $(7,9)$; бетулиновый альдегид $(1,2)$. На основе бетулина синтезируют перспективные фармацевтические препараты с противоопухолевой и антивирусной активностью. Бетулин используется также в производстве шампуней, мыла и другой парфюмерно-косметической продукции [2]. Доступность и биологическая активность бетулина ставят его в ряд ценных природных источников для использования как в нативном состоянии, так и в виде различных продуктов трансформации.

Наиболее распространенные методы выделения бетулина основаны на экстракции бересты различными растворителями в аппарате Сокслета, а также на щелочном гидролизе бересты с последующей экстракцией бетулина.

С целью интенсификации процесса получения бетулина предложено активировать бересту в условиях неизобарного парокрекинга при температуре 180-260 들 давлении 2-5 МПа, продолжительности активации 1-5 мин в присутствии щелочи (щелочной гидролиз), взятой в количестве 5-20\% от веса абсолютно сухой бересты (а.с.б.) с последующей экстракцией бетулина спиртом [3].

Изучено влияние ударно-акустического воздействия (УАВ) на процесс обработки бересты смесью вода - этанол - щелочь [4]. Выявлено, что УАВ в течение 5 мин при температуре $70{ }^{\circ} \mathrm{C}$ интенсифицирует гидролиз бересты, которая превращается в гомогенную массу коричневого цвета.

Известно, что одним из эффективных способов экстракции растительных материалов является мик-

Коптелова Елена Николаевна - аспирант кафедры лесохимических производств, тел.: (8182) 21-61-76, e-mail: elen-koptelova@yandex.ru

Кутакова Наталья Алексеевна - профессор кафедры лесохимических производств, кандидат технических наук, тел.: (8182) 21-61-76, e-mail: lesochim@agtu.ru Третьяков Сергей Иванович - профессор кафедры лесохимических производств, кандидат технических наук, тел.: (8182) 21-61-76, e-mail: lesochim@ agtu.ru роволновая обработка в сверхвысокочастотном (СВЧ) поле.

Например, экстракция этиловым спиртом в СВЧ-поле при получении кедрового масла позволяет значительно интенсифицировать процесс, сохранить биологическую ценность компонентов и получить высококачественные экологически чистые продукты. Оптимальные технологические параметры процесса

\footnotetext{
*Автор, с которым следует вести переписку.
} 
извлечения масла из семян кедра сибирского в СВЧ-поле следующие: удельная мощность 0,18-0,20 кВтч/кг; гидромодуль 1,25-1,5; продолжительность процесса экстракции 4-6 мин [5].

В работе [6] исследовано влияние СВЧ-поля на экстракцию арабиногалактана (АГ) из древесины лиственницы. После водной экстракции опилок лиственницы при микроволновом излучении мощностью 800 Вт в течение 0,5 мин выход АГ составляет $24,6 \%$ от массы абсолютно сухой древесины, что сокращает на два порядка продолжительность процесса по сравнению с традиционными вариантами экстракции при одновременном увеличении выхода и чистоты арабиногалактана.

Характер воздействия СВЧ-поля сходен с интенсивной влаготепловой обработкой, проводимой путем сочетания обработки острым паром и кондуктивного нагрева, но разрушение структуры при СВЧ-поле происходит в большей степени. Явления парообразования и расширения воздуха в капиллярах и пустотах, возникающие под воздействием микроволновой обработки, создают избыточное давление в отдельных зонах микроструктуры, что вызывает более серьезные разрушения клеточной структуры по сравнению с действием кондуктивного нагрева [7].

Цель настоящей работы - изучение интенсификации процесса выделения экстрактивных веществ (ЭВ) и бетулина из бересты с использованием СВЧ-поля.

\section{Экспериментальная часть}

В качестве исходного сырья использовали техническую бересту с Архангельского фанерного завода в виде стружки - молотая береста (Б1), где основная фракция на основе ситового анализа составила от 2 до 5 мм, что составляет $85,2 \%$ от общей массы бересты.

Для молотой бересты рассчитывали эквивалентный диаметр $\left(\mathrm{d}_{3}\right)$ по формуле:

$$
d_{\ni}=\sum_{i=1}^{N} x_{i} d_{n},
$$

где $\mathrm{N}$ - число фракций; $\mathrm{x}_{\mathrm{i}}$ - массовые доли отдельных фракций; $\mathrm{d}_{\mathrm{n}}$ - средние диаметры бересты отдельных фракций, мм; $d_{n}=\sqrt{d_{1}} d_{2}, \mathrm{~d}_{1}$ и $\mathrm{d}_{2}-$ линейные размеры отверстий сит, между которыми задержалась частица, мм.

Также готовили модельные образцы бересты с фиксированными размерами в тангенциальном, продольном и радиальном направлениях путем разрезания - Б2-Б5.

Экстракцию вели в СВЧ камере, которая состояла из магнетрона, экстракционной колбы, мешалки, амперметра, обратного холодильника (рис. 1). Бересту загружали в колбу, заливали соответствующим количеством подогретого экстрагента. Затем колбу помещали в СВЧ-камеру, подсоединяли ее к обратному холодильнику, включали мешалку и экстрагировали в течение 6-7 мин при расходе энергии 0,04 кВТ·ч. Для определения числа оборотов мешалки использовался прибор «Фототахометр бесконтактный цифровой 2234А». По истечении времени полученную массу отфильтровывали. Полученный этанольный экстракт бересты упаривали до $1 / 3$, затем добавляли горячую воду в соотношении экстракт - вода (1:1). В водноспиртовой смеси бетулин-сырец выпадал в осадок, его отделяли фильтрованием и высушивали до постоянной массы в сушильном шкафу при $60{ }^{\circ} \mathrm{C}$.

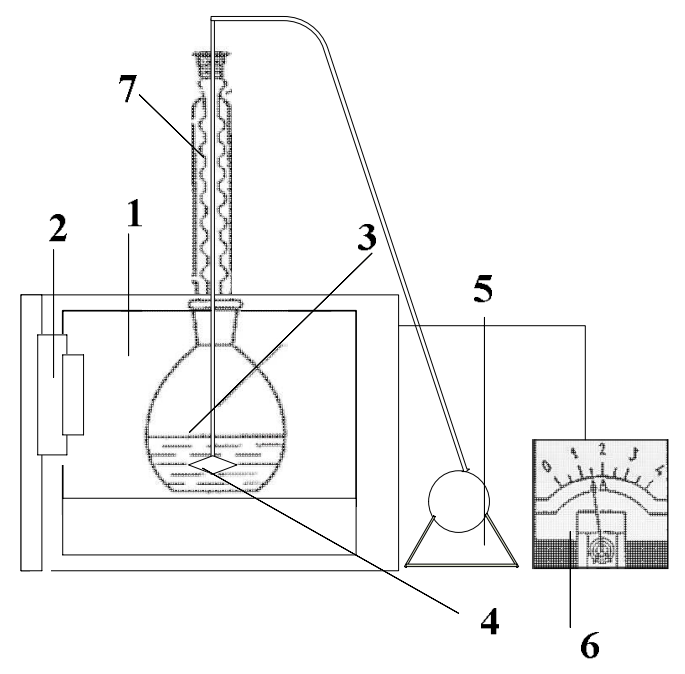

Рис. 1. Схема установки для СВЧ-экстракции: 1 - камера с подводом электромагнитного поля СВЧ; 2 - магнетрон; 3 - экстракционная колба; 4 - мешалка; 5 - привод мешалки; 6 - амперметр; 7 - обратный холодильник 
При исследовании кинетики извлечения ЭВ и бетулина из бересты периодически (через 1 мин) производили отбор экстрактов. За нарастанием концентрации ЭВ следили с помощью весового метода (высушивание отобранного объема раствора). Количественное содержание бетулина в экстракте определяли с помощью метода ВЭЖХ (высокоэффективной жидкостной хроматографии). В качестве стандарта использовали двукратно перекристаллизованный бетулин из этилацетата.

Метод ВЭЖХ реализован на хроматографе LC-20 фирмы Shimadzu. Колонка Zorbax Eclipce Pluse $\mathrm{C}-18,3 \times 100 \mathrm{~mm}$, размер частиц $3,5 \mu \mathrm{m}$. Температура колонки $40{ }^{\circ} \mathrm{C}$. Хроматографирование проводилось в градиентном режиме подачи элюентов; объем вводимой пробы 2 мкл; скорость потока 0,4 мл/мин. Детектирование - на диодно-матричном детекторе при длине волны 205 нм.

\section{Обсуждение результатов}

Влияние СВЧ-обработки на выход ЭВ, бетулина-сырияа и бетулина. На рисунке 2 показана кинетика извлечения ЭВ и бетулина методом настаивания и СВЧ-экстракцией. 90\%-я степень извлечения ЭВ наблюдается через 90 мин при экстракции по методу настаивания и через 10 мин - в СВЧ-камере. Степень извлечения бетулина по методу настаивания не превышает $40 \%$ за весь период наблюдения, в то время как в СВЧ-поле $-53 \%$ за 10 мин.

Достижение степени извлечения, равной 50\%, при обычной экстракции составляет 16-20 мин, а при СВЧ - менее 1 мин, следовательно, скорость экстрагирования в СВЧ-поле повышается в 10-15 раз.

Из графиков (рис. 3) видно, что кривые экстрагирования (зависимость степени извлечения от $\sqrt{\tau}$ ) методом настаивания имеют s-образный характер, что указывает на существование сорбционного взаимодействия между скелетом бересты и извлекаемыми ЭВ. Форма кривой экстрагирования близка к изотерме адсорбции. Влияние же адсорбционных сил на кинетику экстракции СВЧ практически неощутимо.

При СВЧ-экстракции бересты спиртом с расходом энергии 0,04 кВт·ч в течение 10 минут выход бетулина-сырца составил $21 \%$ от массы абсолютно сухой бересты (а.с.б.). При проведении эксперимента с помощью традиционного метода экстракции (метод настаивания) в течение 5 ч выход бетулина-сырца составил $20 \%$.

Бетулин-сырец, полученный по методу СВЧ-экстракции, представляет собой светло-серый порошок, без запаха и посторонних включений (с содержанием основного вещества по методу ВЭЖХ 75\%). После перекристаллизации из этилацетата бетулин - порошок белого цвета.

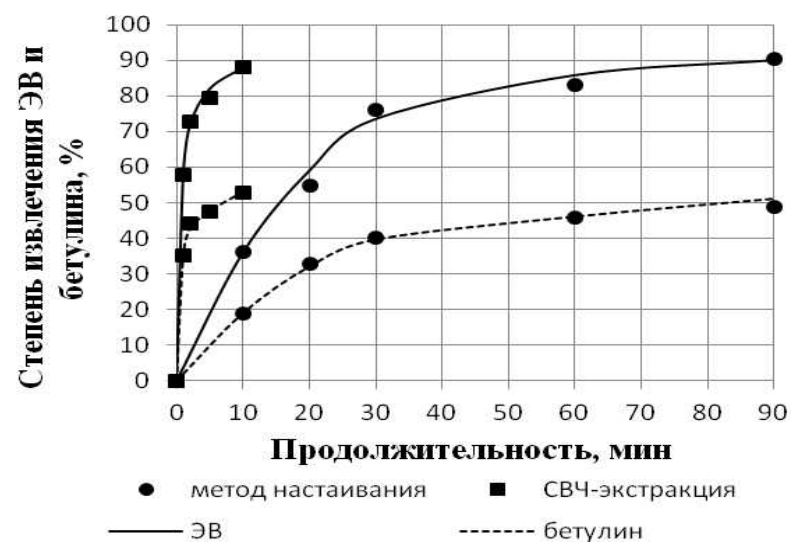

Рис. 2. Влияние СВЧ-обработки и продолжительности экстракции на степень извлечения ЭВ и бетулина различными методами

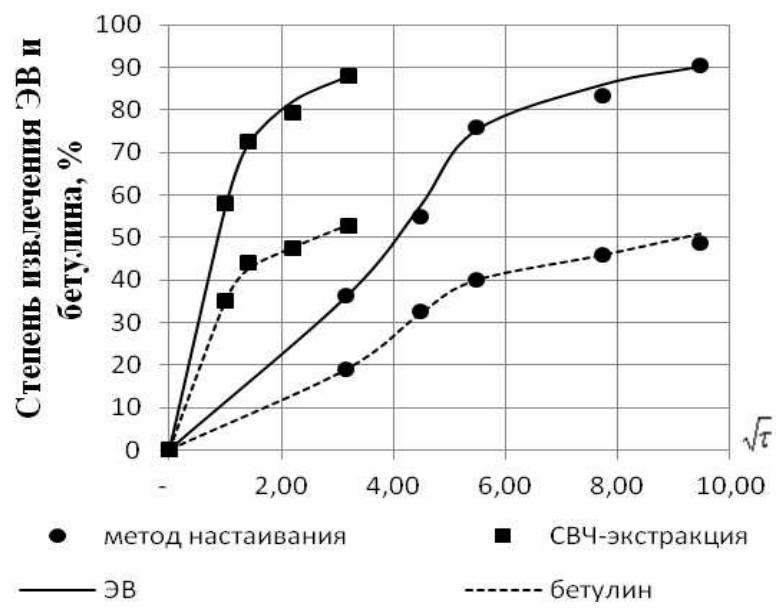

Рис. 3. Зависимость степени извлечения ЭВ и бетулина от $\sqrt{\tau}$ 
Влияние основных параметров на процесс СВЧ-экстрагирования ЭВ из бересты. Большое влияние на процесс экстрагирования оказывает степень и характер измельчения сырья.

На кинетических кривых (рис. 4) и из таблицы видно, что концентрация ЭВ в растворе и выход бетулина-сырца из молотой бересты выше, чем из бересты с фиксированными размерами. Это объясняется тем, что клеточная структура бересты разрушается при размалывании с образованием неровной поверхности сырья. Ровная поверхность и определенный размер кусочкам сырья придаются при резании, при этом сохраняется клеточная структура. Быстрее экстрагируется сырье, клеточная структура которого разрушена больше, так как возрастает поверхность экстракции и усиливается процесс вымывания ЭВ из разрушенных клеток.

Однако с увеличением размеров бересты по длине происходит незначительное снижение скорости процесса экстракции и уменьшение степени извлечения ЭВ.

На кинетических кривых для всех образцов можно выделить два периода процесса. Первый (I) из них (криволинейный участок) характеризуется переносом ЭВ с поверхности бересты из пор, наиболее доступных для раствора. Продолжительность первой стадии 4-5 мин. Во второй стадии (II) (прямолинейный участок) раствор проникает во все доступные для него поры и капилляры, растворяет извлекаемые ЭВ и перемещает их к поверхности частицы. Эта стадия наиболее продолжительна.

На перенос ЭВ в первой стадии значительное влияние оказывает перемешивание (рис. 5). Выход бетулина-сырца при скорости 1684 об/мин составляет 19\%, при 845 об/мин - 17,3\%, при 67 об/мин - 16\% от а.с.б.

Отсюда следует, что внешняя массоотдача является лимитирующей стадией процесса экстрагирования в этот период.

Соотношение фаз (жидкостной модуль) - один из основных параметров, определяющих процесс извлечения ЭВ из бересты. При выборе жидкостного модуля необходимо учитывать растворимость веществ в экстрагенте. В работе [8] определена растворимость бетулина-сырца, перекристаллизованного (очищенного) бетулина и ЭВ бересты в этиловом спирте при различной температуре. Показано, что очищенный бетулин при температуре кипения имеет наименьшую растворимость $(2,03 \%)$ по сравнению с ЭВ $(6,41 \%)$. Поэтому минимальный модуль для процесса экстракции должен быть не менее $5: 1$.

При проведении СВЧ-экстракции с вариацией модуля от $10: 1$ до $20: 1$ (по объему) при расходе энергии 0,04 кВт·ч в интервале продолжительности процесса до 10 мин установлено, что максимальное извлечение ЭВ из бересты наблюдается через 5-6 мин, независимо от модуля экстракции (рис. 6). Причем вариация модуля показала, что при модуле $20: 1$ извлекается на 7-8\% больше ЭВ, чем при модуле $10: 1$.

Выход бетулина-сырца в зависимости от степени и вида измельчения бересты

\begin{tabular}{c|c|c}
\hline Образец & $\begin{array}{c}\text { Эквивалентный диаметр и размеры частиц в тангенциальном, } \\
\text { продольном и радиальном направлениях, мм }\end{array}$ & $\begin{array}{c}\text { Выход бетулина-сырца, } \\
\text { процент от а.с.б. }\end{array}$ \\
\hline Б1 & $\mathrm{d}_{3}=3,36$ & 21,0 \\
Б2 & $2,6 \cdot 2,5 \cdot 1,5$ & 11,3 \\
Б3 & $2,5 \cdot 5,1 \cdot 1,6$ & 8,9 \\
Б4 & $2,5 \cdot 7,5 \cdot 1,5$ & 8,0 \\
Б5 & $2,6 \cdot 10 \cdot 1,5$ & 6,9 \\
\hline
\end{tabular}

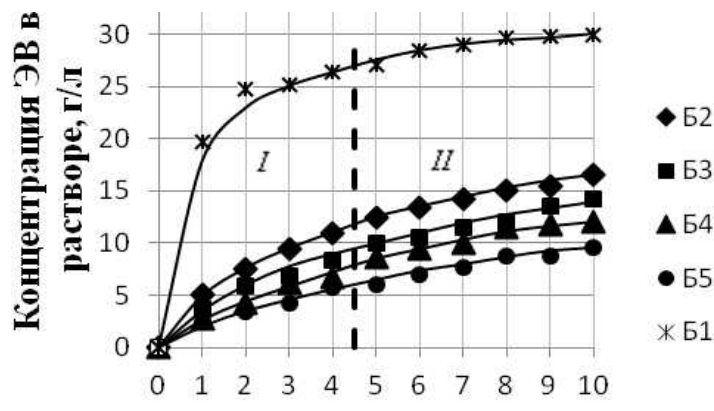

Продолжительность, мин

Рис. 4. Кинетические кривые экстракции ЭВ из бересты в зависимости от степени измельчения

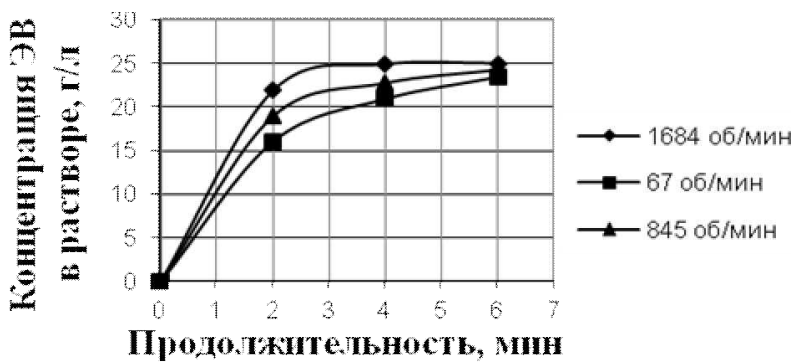

Рис. 5. Кинетические кривые экстракции ЭВ из бересты в зависимости от скорости 
перемешивания

Рис. 6. Кинетические кривые экстракции ЭВ из бересты в зависимости от гидромодуля процесса

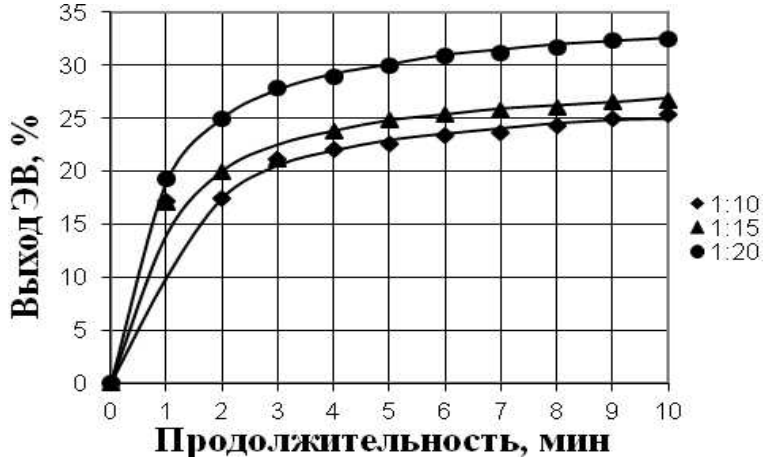

\section{Вblводы}

Экстракция бересты с использованием микроволновой обработки в СВЧ-поле позволяет сократить в 10-15 раз продолжительность процесса по сравнению с традиционными методами экстракции, длительность которых составляет несколько часов.

Изучено влияние основных параметров на процесс СВЧ-экстрагирования: степень измельчения сырья, скорость перемешивания и жидкостной модуль процесса. Показано, что оптимальными условиями для максимального извлечения ЭВ и бетулина из бересты являются продолжительность процесса 5-6 минут, модуль 20 : 1. Установлено два периода экстракции: быстрый и медленный. В первый период экстрагирования внешняя массоотдача является лимитирующей стадией процесса.

Высокоэффективная жидкостная хроматография осуществлена на хроматографе LC-20 фирмы Shimadzи в Центре коллективного пользования Северного (Арктического) федерального университета им. М.В. Ломоносова.

\section{Список литературы}

1. Кислицын А.Н. Экстрактивные вещества бересты: выделение, состав, применение. Обзор // Химия древесины. 1994. №3. С. 3-28.

2. Казакова О.Б., Толстиков Г.А. Медицинские перспективы использования тритерпеноидов лупанового ряда // Химия в интересах устойчивого развития. 2008. №16. С. 727-730.

3. Кузнецов Б.Н. Выделение бетулина и суберина из коры березы, активированной в условиях «взрывного автогидролиза» // Химия растительного сырья. 1998. №1. С. 5-9.

4. Патент 2264411 (РФ). Способ получения бетулина / С.А. Кузнецова, Б.Н. Кузнецов, А.Г. Михайлов, В.А. Левданский / БИ. 2005. №27.

5. Ширеторова В.Г. Разработка основ технологии получения кедрового масла СВЧ-экстракцией спиртом этиловым: дис. ... канд. техн. наук. Улан-Удэ, 2002. 155 с.

6. Кузнецова С.А., Михайлов А.Г., Скворцова Г.П., Александрова Н.Б. Интенсификация процесса водной экстракции арабиногалактана из древесины лиственницы // Химия растительного сырья. 2005. №1. С. 53-58.

7. Бадмацыренов Б.В. Разработка оборудования и процесса экстракции кедрового масла в электромагнитном поле СВЧ: дис. ... канд. техн. наук. Улан-Удэ, 2004. 147 с.

8. Коптелова Е.Н., Минина А.В., Кутакова Н.А., Третьяков С.И. Определение растворимости бетулина // Химия поверхности и нанотехнология: сб. мат-лов всерос. молодежной конф. Казань, 10-11 октября, 2012. С. 118. 
Koptelova E.N. ${ }^{*}$, Kutakova N.A., Tretyakov S.I. REMOVING THE EXTRACTIVES AND BETULIN FROM BIRCH BARK EXPOSED MICROWAVE FIELD

Northern (Arctic) Federal University, M.V. Lomonosov, Naberezhnaia Severnoi Dviny, 17, Arkhangelsk, 163002

(Russia), e-mail: elen-koptelova@yandex.ru

Removing the extractives and betulin from birch bark exposed microwave field. The process of recovery of extractives and betulin from birch bark under the influence of the microwave field. It is shown that the use of microwave treatment in a microwave field the duration of the extraction process is reduced by 10-15 times compared with extraction by infusion. The influence of the main parameters of the process of microwave extraction of extractive substances from birch bark.By high performance liquid chromatography to quantify the content of betulin found in the birch bark extract.

Keywords: birch bark, microwave extraction, extractives, betulin.

\section{References}

1. Kislitsyn A.N. Khimiia drevesiny, 1994, no. 3, pp. 3-28. (in Russ.).

2. Kazakova O.B., Tolstikov G.A. Khimiia v interesakh ustoichivogo razvitiia, 2008, no. 16, pp. 727-730. (in Russ.).

3. Kuznetsov B.N. Khimiia rastitel'nogo syr'ia, 1998, no. 1, pp. 5-9. (in Russ.).

4. Patent 2264411 (RU). 2005. (in Russ.).

5. Shiretorova V.G. Razrabotka osnov tekhnologii polucheniia kedrovogo masla SVCh-ekstraktsiei spirtom etilovym: dis. ... kand. tekhn. nauk. [Developing a framework of cedar oil technology for microwave extraction with ethyl alcohol: candidate of technical science dissertation]. Ulan-Ude, 2002, 155 p. (in Russ.).

6. Kuznetsova S.A., Mikhailov A.G., Skvortsova G.P., Aleksandrova N.B. Khimiia rastitel'nogo syr'ia, 2005, no. 1, pp. 53-58. (in Russ.).

7. Badmatsyrenov B.V. Razrabotka oborudovaniia i protsessa ekstraktsii kedrovogo masla v elektromagnitnom pole SVCh: dis. ... kand. tekhn. nauk. [Development of equipment and cedar oil extraction process in the electromagnetic field of the microwave: candidate of technical science dissertation]. Ulan-Ude, 2004, 147 p. (in Russ.).

8. Koptelova E.N., Minina A.V., Kutakova N.A., Tret'iakov S.I. Khimiia poverkhnosti i nanotekhnologiia: materialy vseros. molodezhnoi konf. [Surface Chemistry and Nanotechnology: Materials of the Russian Youth Conference]. Kazan, 2012, pp. 118. (in Russ.).

Received December 19, 2012

\footnotetext{
* Corresponding author.
} 